\title{
Effects of Energy Storage Systems on Fuel Economy of Hybrid-Electric Vehicles
}

\author{
* Godwin K. Ayetor, Emmanuel Duodu, John Abban
}

Faculty of Engineering, Koforidua Polytechnic, , Koforidua, Ghana.

*kafuiayetor@yahoo.co.uk

\begin{abstract}
Three energy storage systems, namely Nickel Zinc, Nickel Metal Hydride and Lithium ion batteries were simulated on ADVISOR (Advanced vehicle simulator) to determine their impact on fuel economy. ADVISOR, a drivetrain analysis tool developed in MATLAB/Simulink for comparing fuel economy and emissions performance and designed by the National Renewable Energy Laboratory by Ford, GM, and Chrysler was used for the simulations. In choosing the batteries for simulations, only the latest technological advanced batteries of $\mathrm{NiZn}, \mathrm{Li}$ ion and $\mathrm{NiMH}$ were used. The results showed that NiZn battery influence in fuel economy and system efficiency far exceeds the other batteries especially for the combined Powertrain. While a lithium ion battery is seen to be well suited for Parallel and Series powertrains at higher speeds, average values for all drive cycle singles out NiZn as a better performing battery. NiMH showed the worst performance. This confirms NiMH, which is the predominant energy storage system today in the HEV industry, is deficient in advancing the growth of HEV's.
\end{abstract}

Keywords: power trains; hybrid energy storage; hybrid electric vehicle; combined hybrid; parallel hybrid

\section{Introduction}

Ever rising crude oil prices and stricter standard emission regulations have put a lot of pressure on automotive manufacturers to produce more fuel efficient and zero emission cars(Cao and Emadi, 2012, Dagci et al., 2015). Developing Powertrain systems for automotive vehicles with higher fuel efficiency and lesser emissions without sacrificing high performance level is an enormous challenge to the automotive industry (Bayindir et al., 2011). By combining benefits of electric vehicles and conventional vehicles, Hybrid electric vehicles are known to produce almost zero emissions, low noise, and faster responses hence are more reliable (Ayetor et al., 2013, Chung and Hung, 2015). A hybrid electric vehicle (HEV) is described as one with two energy storage systems both of which must provide propulsion together or independently (Tate et al., 2008, Cuma and Koroglu, 2015). The sources of propulsion have both conventional IC engine or fuel cells and electric motors. There are approximately 40 various viable hybrid topologies each having specific advantages and drawbacks (Yilmaz and Krein, 2013).
All these topologies are somewhat variants of Series and Parallel hybrids.

Generally, parts of HEV include IC engine, electric motor, battery, power control unit, and reduction gear. For Series and Combined types, additional generator is required. Combined types have a Power Split device to split traction power between the engine and electric motor.

\subsection{Motivation}

Presently hybrid electric vehicles have mainly been advertised for their ability to minimize fuel consumption and eliminate emissions (Lee and Hogt, 2010). This has primarily been achieved through addition or improvement of a traction motor/generator which supplements the IC engine. Fuel savings have been recorded mainly where more of the electrical energy is used instead of the IC engine(Carlson et al., 2010). Useful attributes of fuel savings and fewer emissions are contradicted by the overall cost of a hybrid electric vehicle (Parks et al., 2007, Chan, 2007). Even though over the entire life of an HEV the running cost will be lesser, most 
consumers might not even need a car for that long (Egbue and Long, 2012). If HEV's are to become competitive then drastic reduction in cost must be considered. Batteries contribute significantly to overall cost of the hybrid vehicle; therefore the need for a lower cost yet efficient battery cannot be overemphasized (Offer et al., 2010, Sulaiman et al., 2015). It is confirmed that traction battery is the most critical component of the vehicle and will be the most expensive component in most cases (Sabri et al., 2016, Dai et al., 2015). To further increase the range of electric motor operation thereby minimizing engine use, batteries play a very significant role (Hwang et al., 2015).

Lithium batteries (especially lithium polymer) have been researched extensively and are

being considered as the future batteries of HEV. The world record for longest distance travelled on a single battery charge was with Lithium-ion Batteries (Dong et al., 2014). A special 1999 Mitsubishi coupe using Li-ion batteries covered $2124 \mathrm{~km}$ (1330 mi) on a single charge. However, Lithium batteries boast of higher specific energies but very high cost $(50 \%$ greater cost than $\mathrm{NiMH}$ ) coupled with inability to be recycled (Walker, 2015). It is incumbent alternative batteries for HEV's are considered. This research attempts to assess performance of alternative $\mathrm{HEV}$ batteries. Nickel Zinc battery is simulated against Lithium and NiMH. Performance is analysed using the criteria of fuel consumption, energy usage, system efficiency and emissions.

\subsection{Battery specifications}

$\mathrm{HEV}$ require batteries that can be recharged as secondary batteries (Castaings et al., 2016). To increase the output voltage, its cells are placed in series. Battery capacity (Ah) gives

indication of how long a battery can give a certain amount of current. For a rating of $3 \mathrm{Ah}$

and assuming current is $0.5 \mathrm{~A}$, it implies such a battery will be able to deliver $0.5 \mathrm{~A}$ continuously for 6 hours (360mins). Power Density (kW/L) and Energy Density $(\mathrm{kWh} / \mathrm{L})$ are used to answer the question of how much a battery weighs (Farmann et al., 2015, Arbizzani et al., 2015). The higher the values the smaller the batteries will be in volume to deliver energy or power (Song et al., 2015). Specific Energy $(\mathrm{kWh} / \mathrm{kg})$ and Specific Power $(\mathrm{kW} / \mathrm{kg})$ measure the respective values in relation to the weight. A battery of $2 \mathrm{kWh} / \mathrm{kg}$ will deliver the same energy as $1 \mathrm{kWh} / \mathrm{kg}$ but with half the weight of the latter. That is, if specific energy is doubled the weight of battery is cut by half. In selecting a battery, the following must be considered: Energy Density, Power Density, Specific Energy, Specific Power, long life, safety, cost, temperature range, Memory Effect and Recycling (Sun et al., 2016).

\section{Methodology}

ADVISOR is an advanced vehicle simulation software developed by the National Renewable Energy Laboratory to allow studies of advanced vehicles. Three different HEV powertrains have been modelled on ADVISOR in this work. These powertrains include SERIES, PARALLEL and COMBINED (POWER-SPLIT). Each powertrain is tested with each of the batteries: NiZn, NiMH and Lithium ion. The specifications of these batteries were modelled based on their highest performance and current technological advancement.

\subsection{Powertrain Specifications}

The Toyota Prius vehicle was modelled for each of the three Powertrains.

Actual Body Weight=2783 pounds (1398kg)-full tank Vehicle Glider Mass $=918 \mathrm{~kg}$, Vehicle Cargo Mass $=136 \mathrm{~kg}$, Vehicle Coefficient of Drag $=0.3$

Vehicle Frontal Area $=1.746 \mathrm{~m}^{2}$, Vehicle Wheel Base $=2.55 \mathrm{~m}$

Centre of Gravity $=1.542$ from rear axle on empty Prius

\subsection{Fuel Converter}

Fuel Type $=$ Gasoline, Capacity $=1.5 \mathrm{~L}$ Japan Prius Atkinson Cycle Engine

Maximum Power $=43 \mathrm{~kW}$ at $4000 \mathrm{RPM}$, Peak Torque $=75 \mathrm{lb}-\mathrm{ft}$ at $4000 \mathrm{RPM}$

Peak Efficiency $=0.39$, Weight $=137 \mathrm{~kg}$. The Torquespeed graph for the fuel converter is shown in Fig.1.

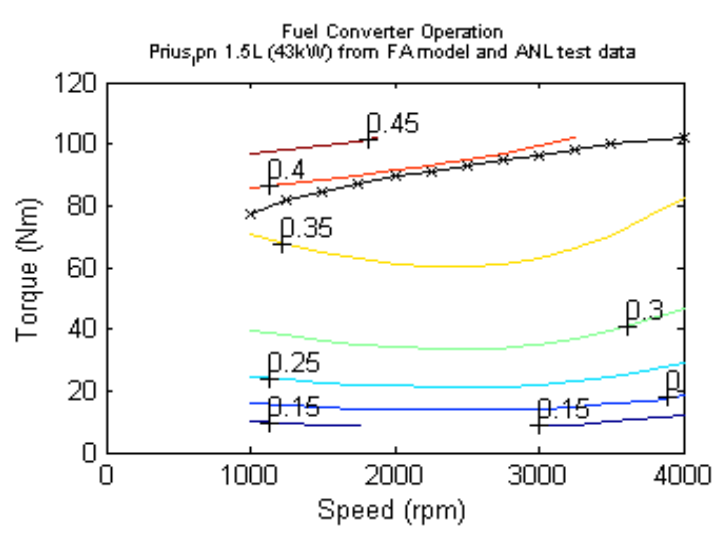

Fig. 1: Torque-Speed operation for fuel converter 


\subsection{Traction Motor}

Specifications for the Traction motor are as follows: Peak Efficiency $=0.91$

Mass $=57 \mathrm{~kg}$, PRIUS_JPN 30-kW permanent magnet motor/controller

\subsection{Generator}

This applies to only the Series and Combined Hybrid only with

PRIUS_JPN 15-kW permanent magnet motor/controller

Peak Efficiency $=0.84$

\section{Weight $=33 \mathrm{~kg}$}

700-W constant electric load accessories were used for the entire simulation.

\subsection{Parallel Powertrain Architecture}

The parallel powertrain architecture used for the modelling on ADVISOR/Matlab is shown in Fig. 2.

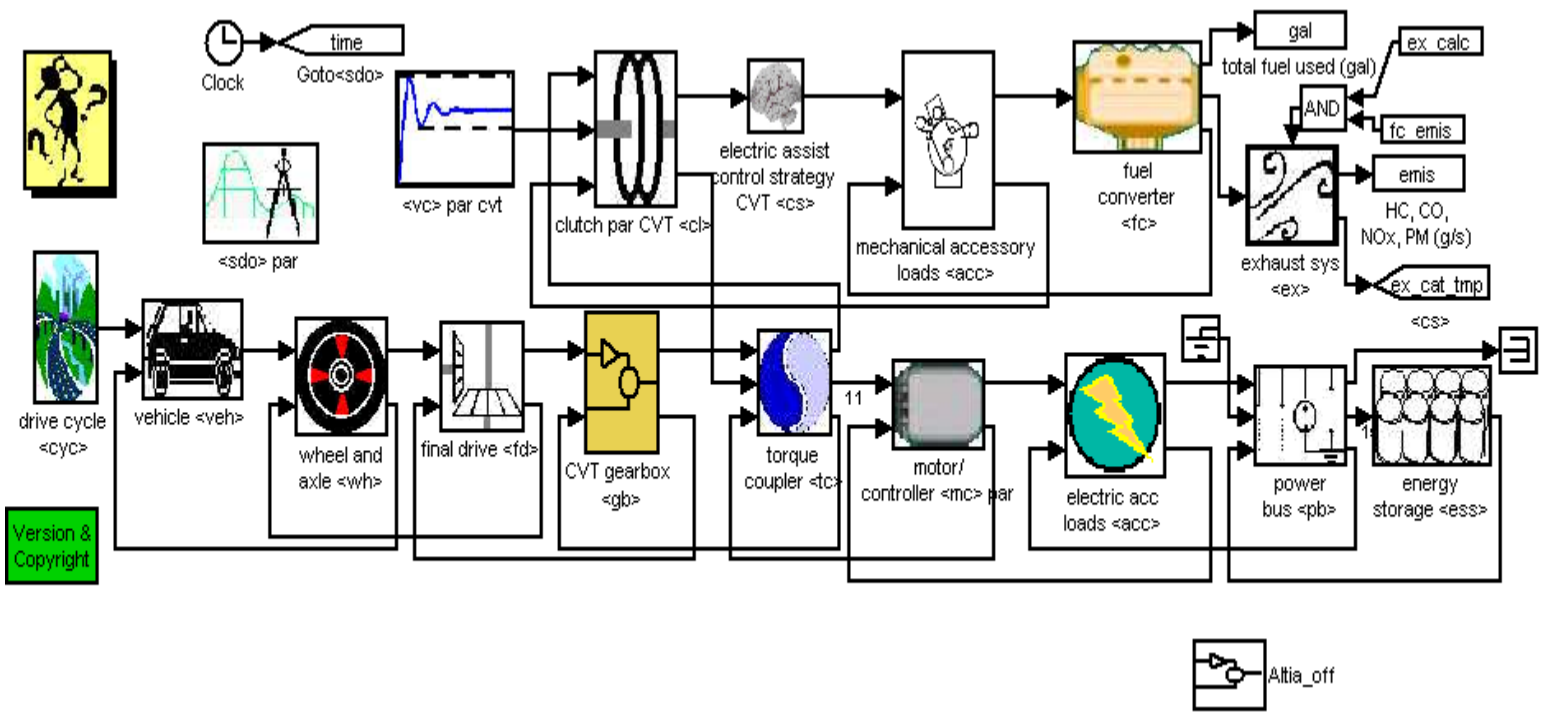

Fig.2: Parallel powertrain as modelled on ADVISOR

\subsection{Series Powertrain Architecture}

Series powertrain architecture modelled on ADVISOR/ Matlab is as shown in Fig. 3

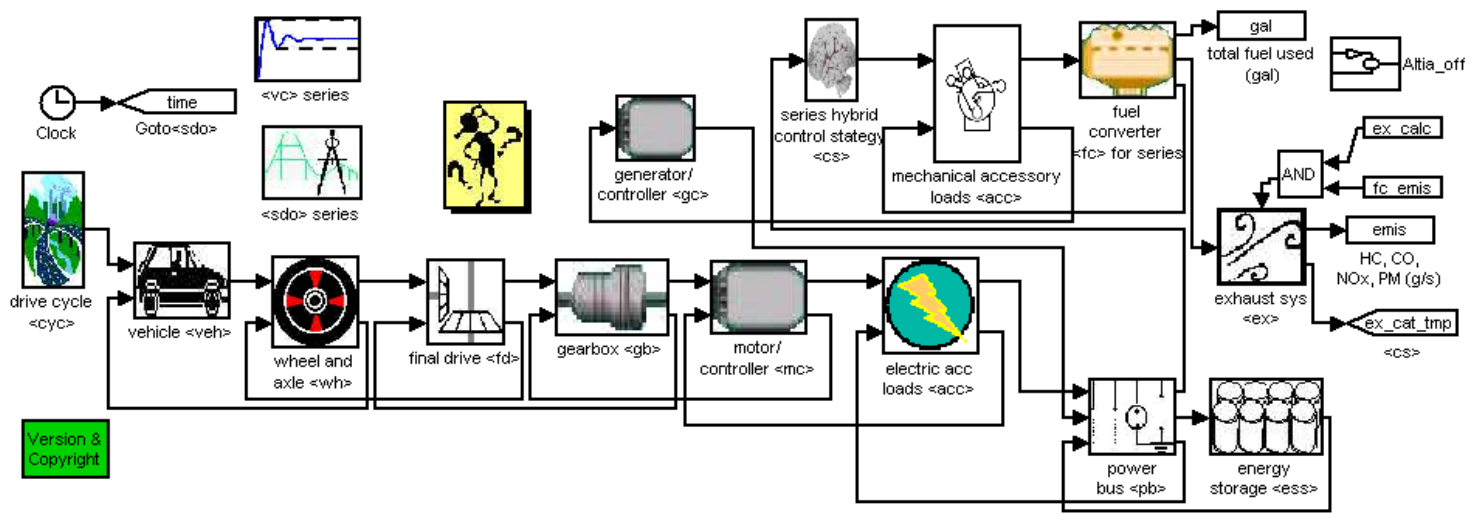

Fig.3: Series powertrain as modelled on ADVISOR 


\subsection{Combined Powertrain Architecture}

A model of the combined hybrid electrical vehicle is shown in Fig. 4

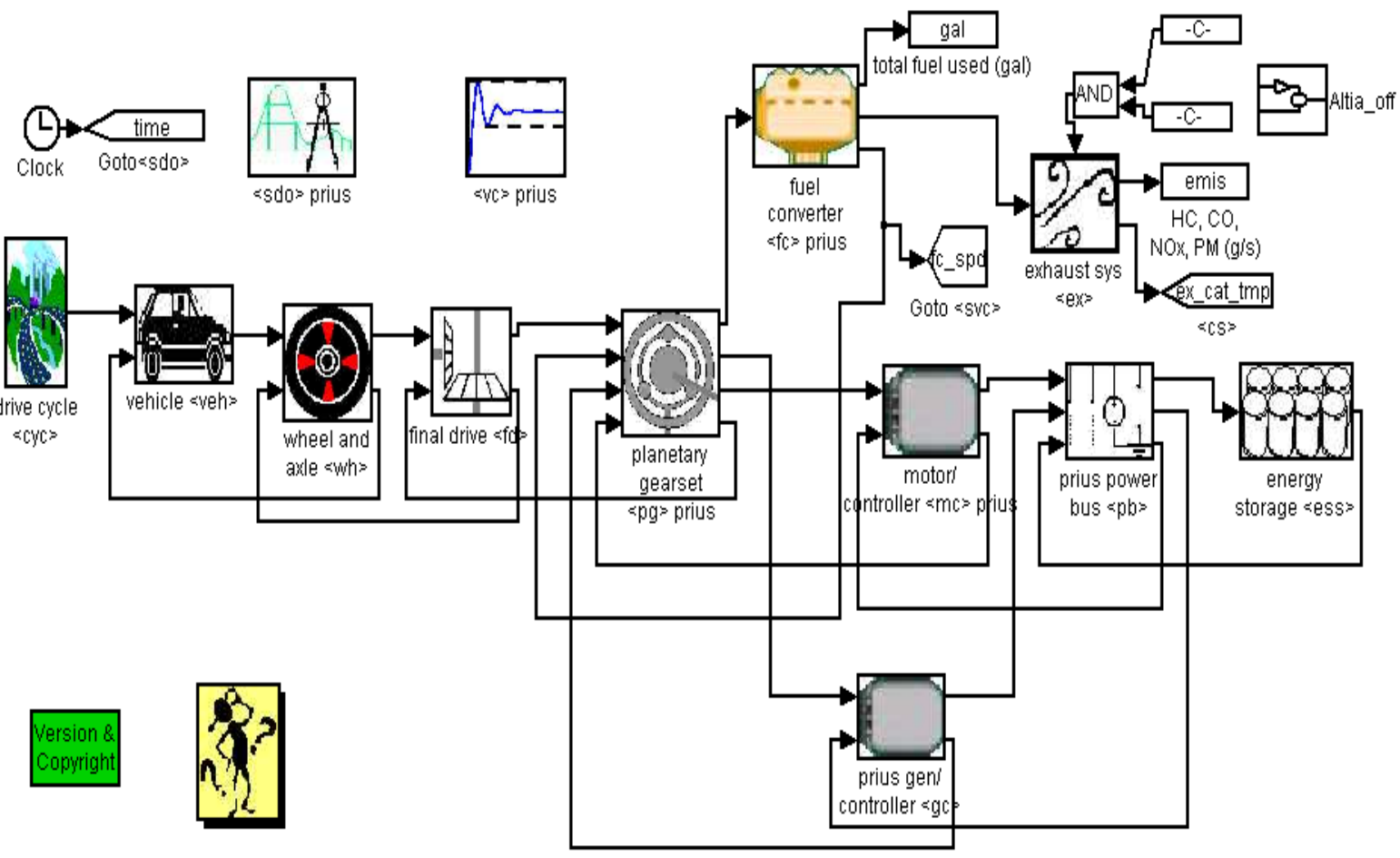

Fig. 4: Combined Powertrain as modelled on ADVISOR

\section{Results and Analysis}

\subsection{Parallel Powertrain (UDDS and NEDC)}

At an average speed of $19.6 \mathrm{mph}(31.54 \mathrm{kph})$ the $\mathrm{NiZn}$ energy storage system was the most fuel efficient (75mpg) as seen from Fig. 5. The NiZn control system was such that battery output power was more than the other batteries at $3511 \mathrm{~kJ}$. As battery power output increases fuel economy is improved hence the results.
Depending on the power demands of an HEV and the State of Charge of the battery, power output must be varied for peak performance and fuel economy. In order to operate in a peak condition, the $\mathrm{NiMH}$ gave the least power output resulting in it having the lowest fuel economy (54mpg). Same fuel economy patterns were recorded for the $\mathrm{New}$ European Drive Cycle (NEDC). 


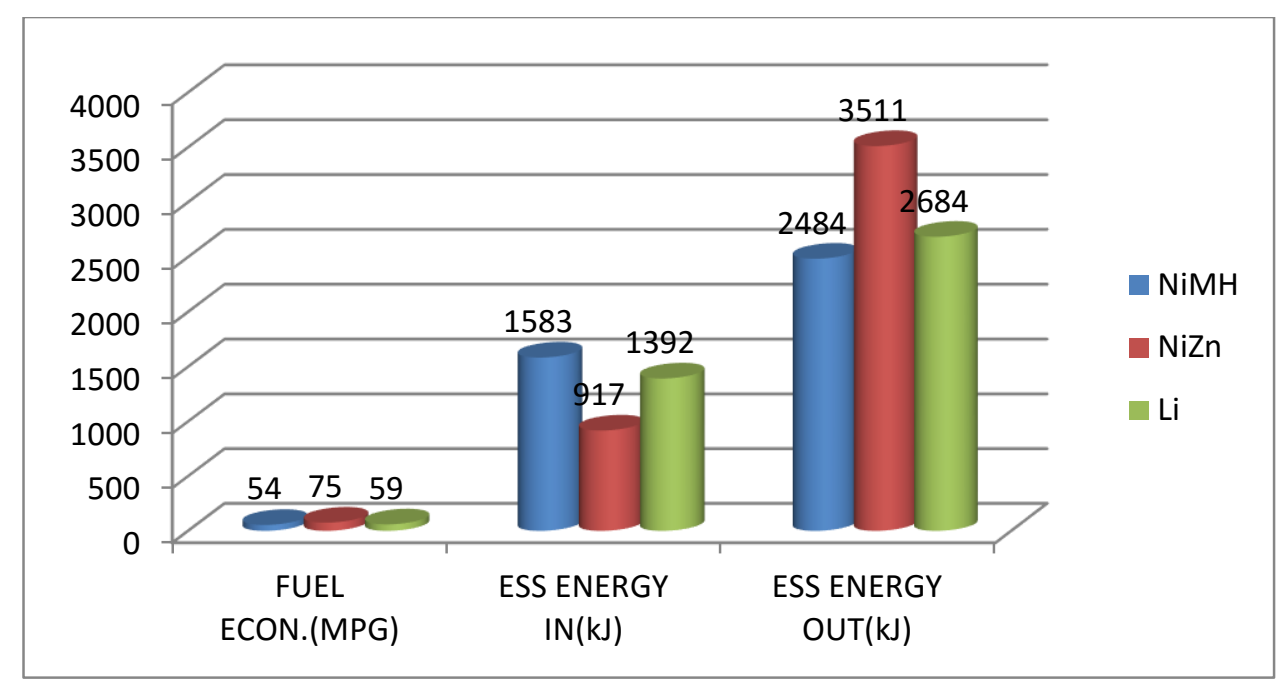

Fig.5: fuel economy of each battery under Parallel powertrain for UDDS

\subsection{Parallel Powertrain Fuel Economy for Highway Fuel Economy Cycle (HWFEC)}

The pattern for the HWFEC differs considerably from UDDS and NEDC. This time best fuel economy $(57 \mathrm{mpg})$ was recorded in the Lithium energy storage system whose control system allows it to give the highest battery power output of $1896 \mathrm{~kJ}$
(Fig.6). Thereby easing the power output of the engine and reducing fuel consumption. The control system regulates power delivery and energy storage based upon the state-of-charges (SoC) of the battery. The lowest energy output for the NiZn system show the battery was recharged more often during the cycle compared to the other systems.

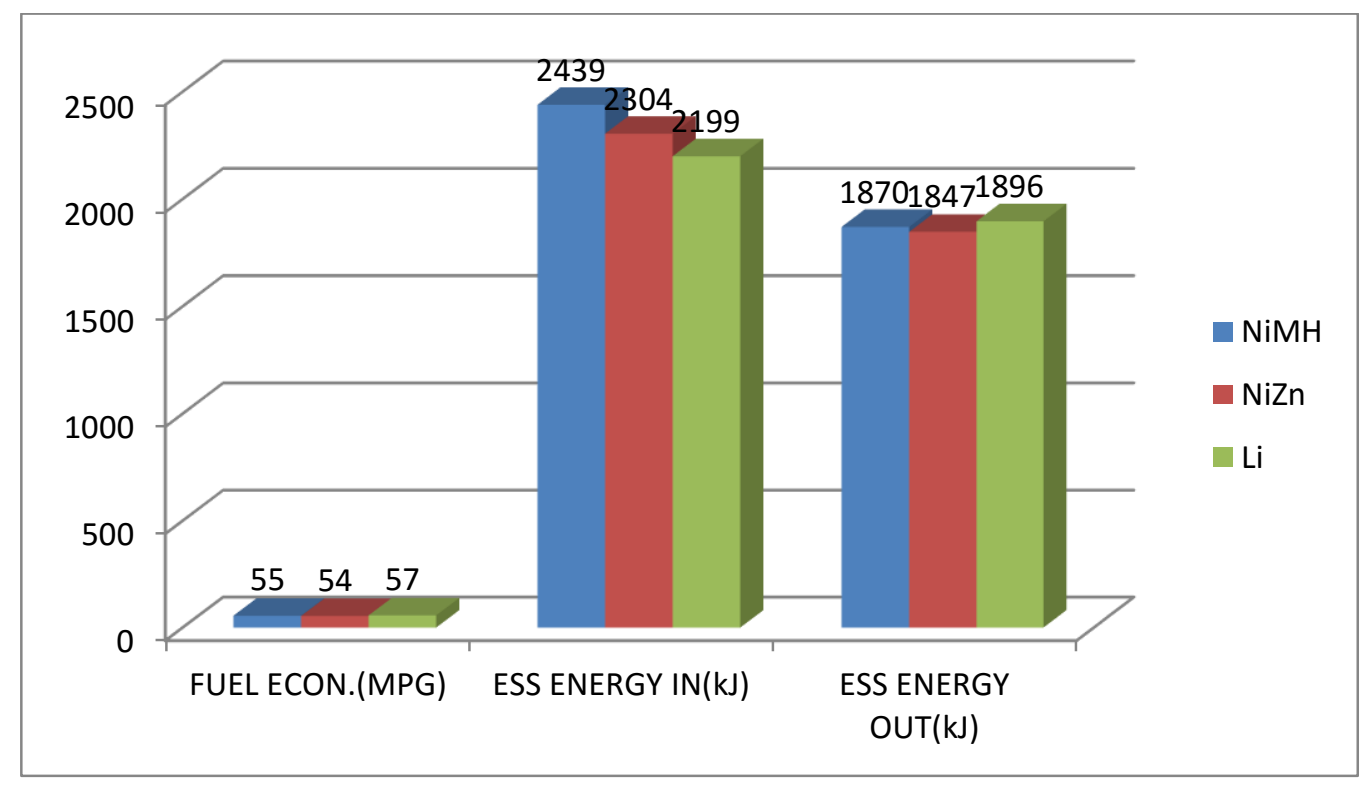

Fig.6: fuel economy of each battery under Parallel powertrain for HWFEC 


\subsection{Combined Powertrain (UDDS and NEDC)}

Fuel economy of the NiZn storage system is $71 \mathrm{mpg}$ and it is by far the highest of the energy storage systems. Its high power output $(3556 \mathrm{~kJ})$ ensures that mostly electrical power is used, thereby lessening the fuel consumption. $48 \mathrm{mpg}$ corresponds to the lowest output of $2215 \mathrm{~kJ}$ for the NiMH storage system (Fig.7). Again, patterns of fuel consumption were the same as for NEDC.

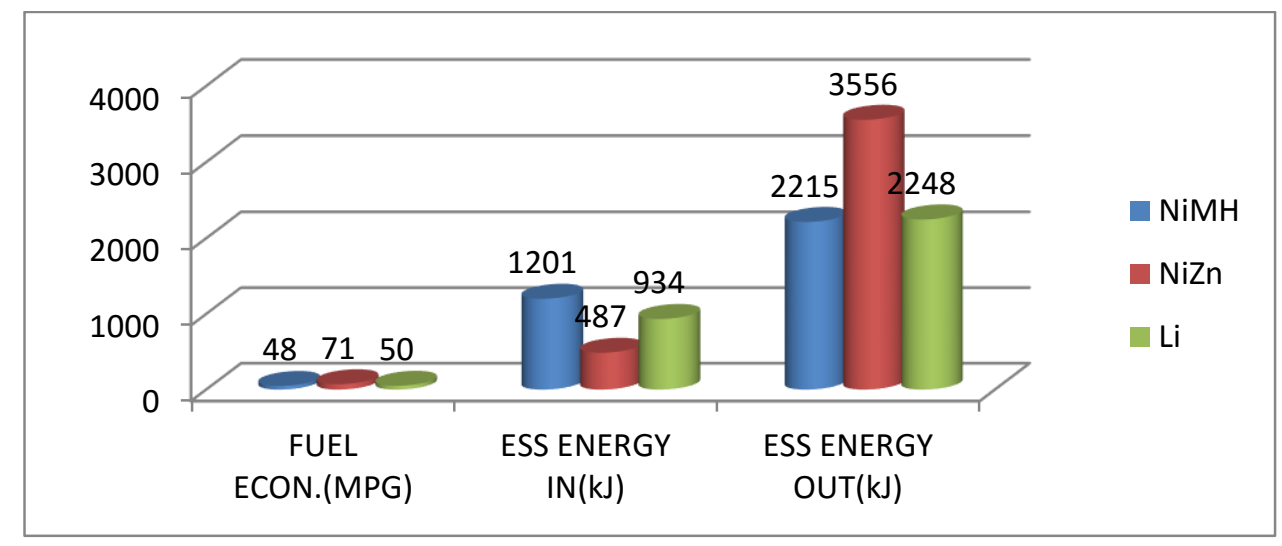

Fig.7: fuel economy of each battery under combined powertrain for UDDS

\subsubsection{Combined Powertrain Fuel Economy Results for High Way Fuel Economy Cycle (HWFEC)}

The patterns remained the same as for the UDDS and NEDC cycle with NiZN again having the highest fuel economy of $77 \mathrm{mpg}$ (Fig.8). Even with the least energy input of $101 \mathrm{~kJ}$, it produced the highest indicating a depleting state of charge for the battery.

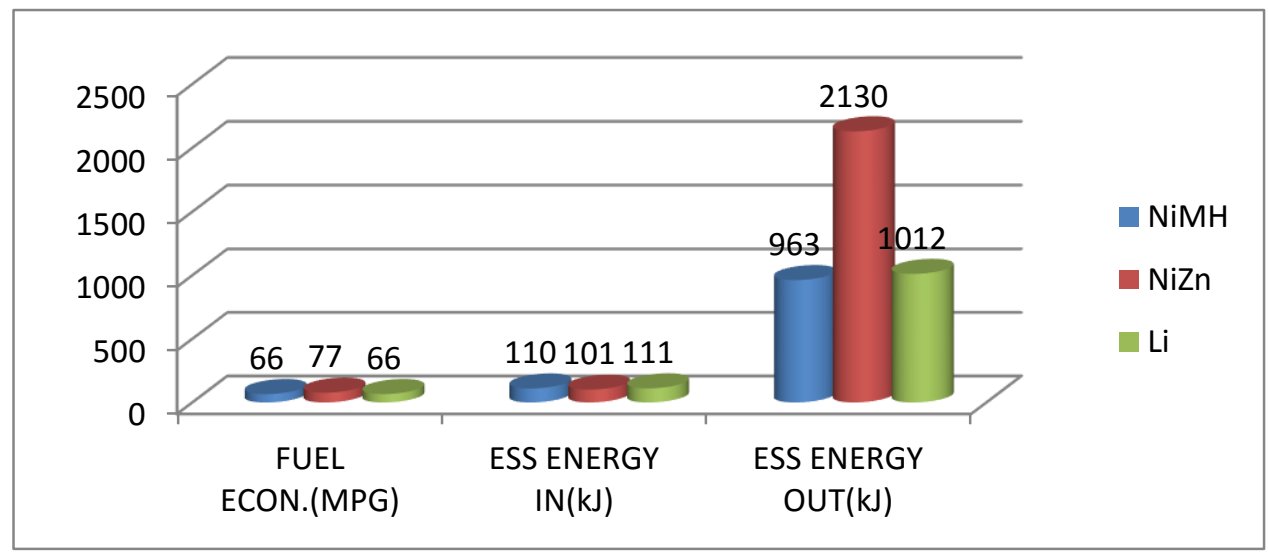

Fig.8: fuel economy of each battery under combined powertrain for HWFEC

\subsection{Series Powertrain Fuel Economy Results for UDDS and NEDC}

The best fuel economy favours NiZn storage system whose SoC shows its discharges energy throughout the entire cycle. This is followed by Lithium ion and $\mathrm{NiMH}$ respectively. It is also noticed that Nickel Zinc had the least input, but highest output (Fig.9). 


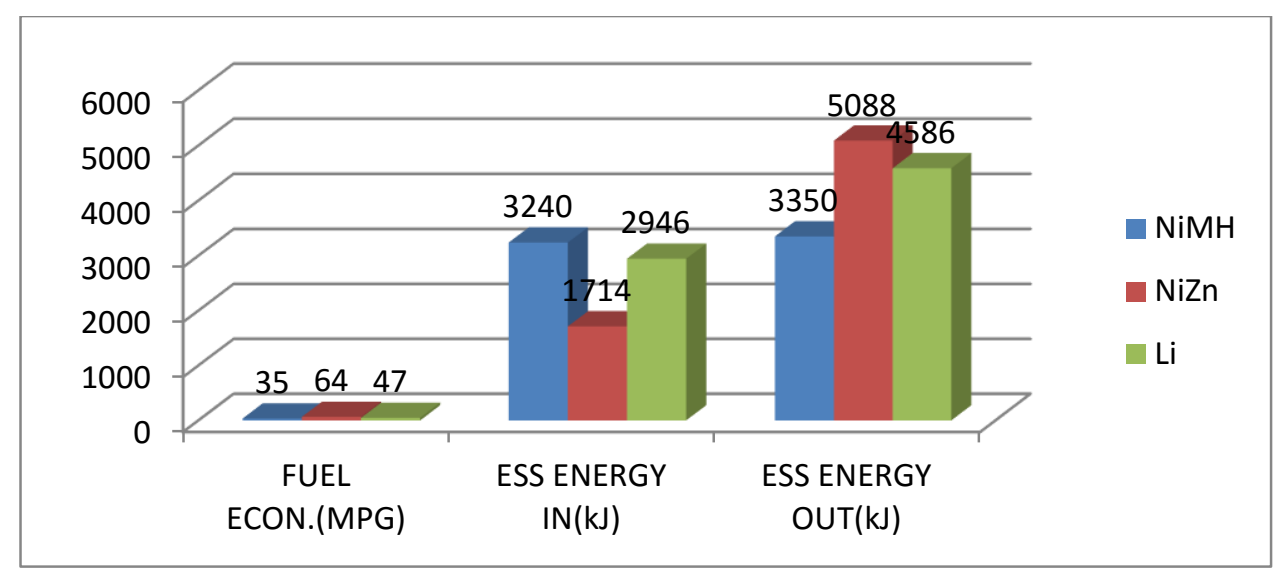

Fig. 9: fuel economy of each battery under Series powertrain for UDDS

\subsubsection{Series Powertrain Results for HWFEC}

For its high battery power contribution to propel the vehicle, Li ion had the highest fuel economy of $55 \mathrm{mpg}$ (Fig.10). The control system is such that the battery state of charge has to be maintained within a limit for optimum performance.

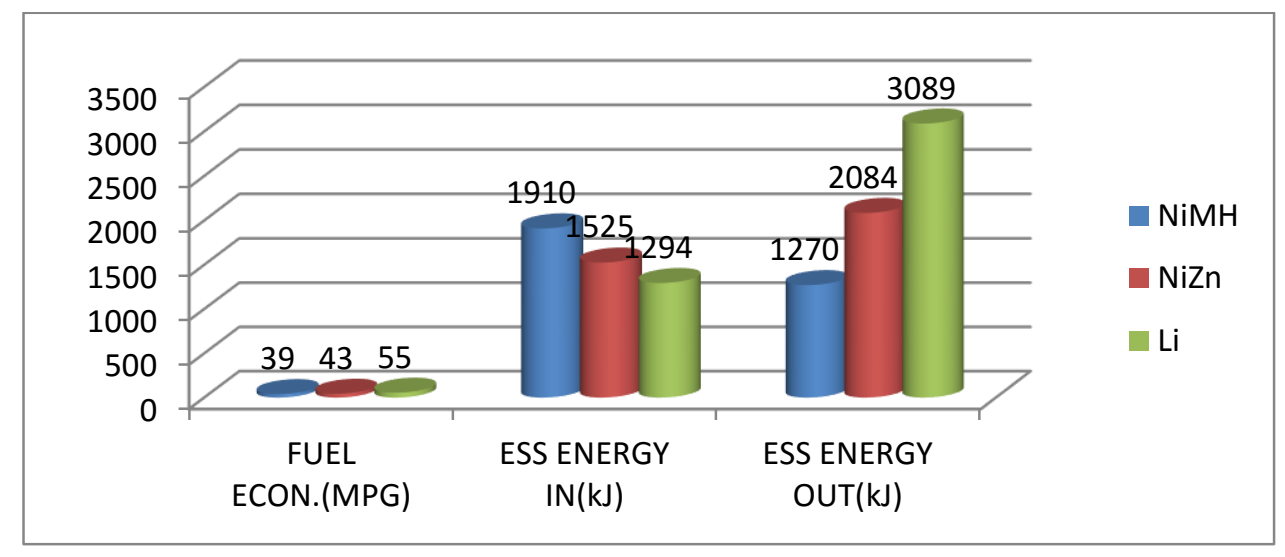

Fig.10: fuel economy of each battery under Series powertrain for UDDS

The SoC for Lithium shows that throughout the cycle, the battery was discharged to as low as 0.4 state of charge (Fig.11).

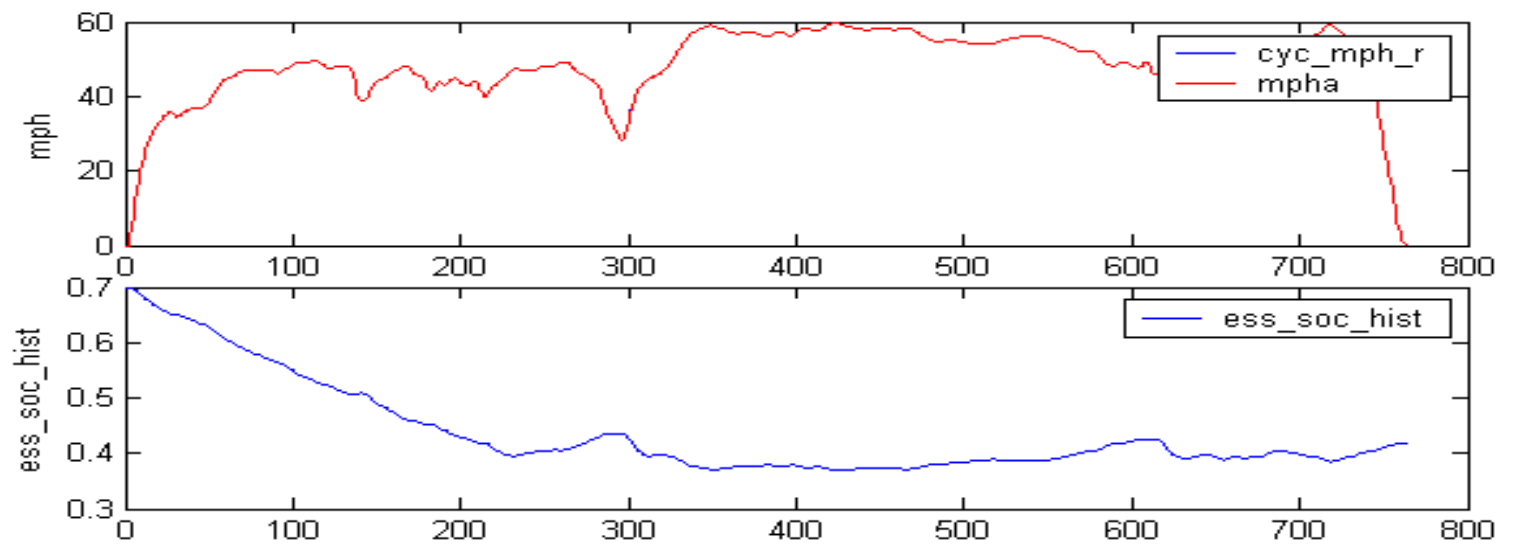

Fig.11:. State of Charge (SoE) for Lithium ion under Series Powertrain for HWFEC 
$\mathrm{NiMH}$ on the other hand operated between 0.76 and 0.68 while recharging for the very first 300 s hence the low output and low fuel economy (Fig.12). This is because during recharging the engine powers the wheels as well as charging the battery consuming a lot of fuel.

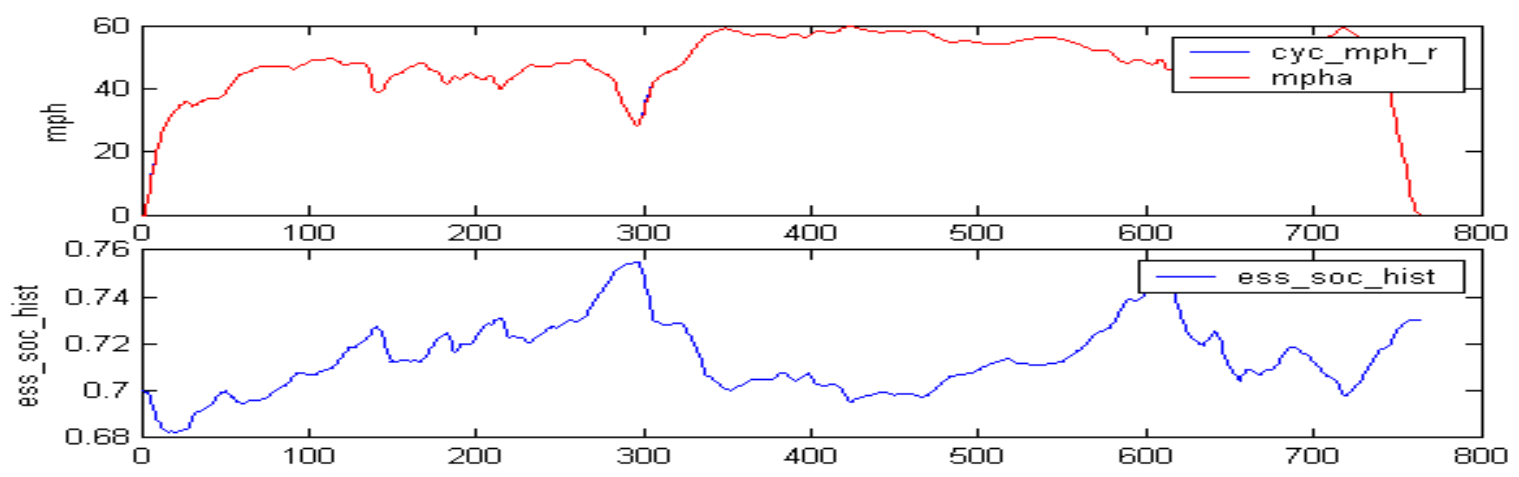

Fig.12: State of Charge (SoE) for NiMH under Series Powertrain for HWFEC

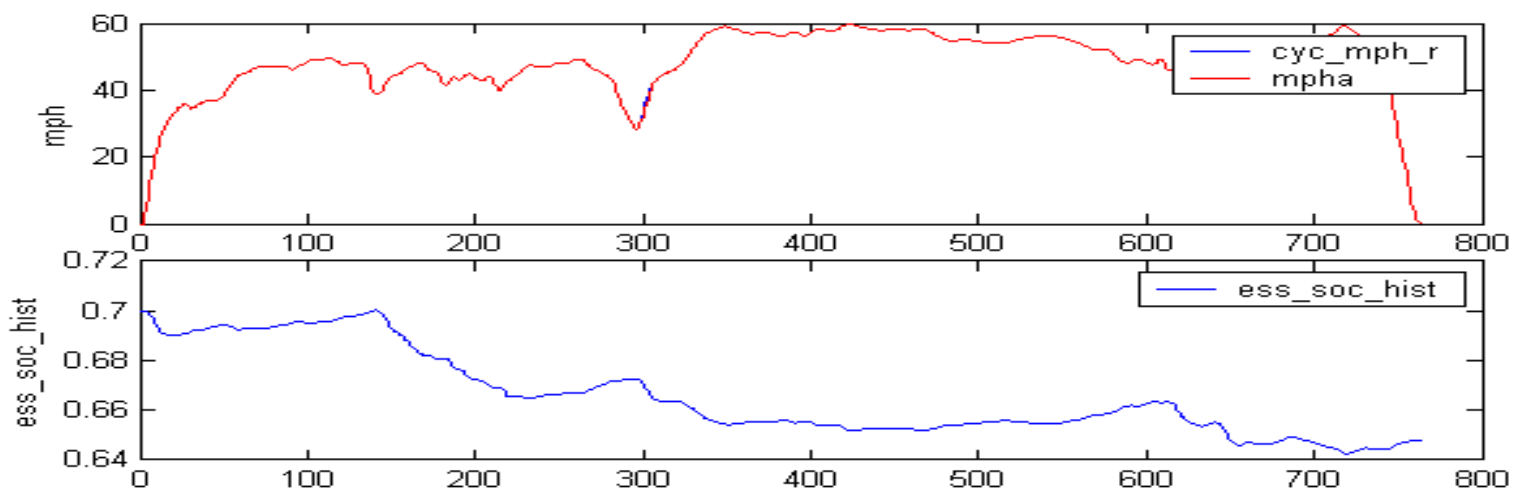

Fig.13: State of Charge (SoE) for NiZn under Series Powertrain for HWFEC

\subsection{Average Values}

For each Powertrain, it is shown from figures 14, 15, 16 that $\mathrm{NiZn}$ is the best for fuel economy and overall system efficiency. For the combined type alone, it achieved an average of $68 \mathrm{mpg}$ compared to $54 \mathrm{mpg}$ and $53 \mathrm{mpg}$ for $\mathrm{Li}$ and $\mathrm{NiMH}$ respectively. Also for almost all the cycles and for all Powertrains, $\mathrm{NiMH}$ showed the worst performance.

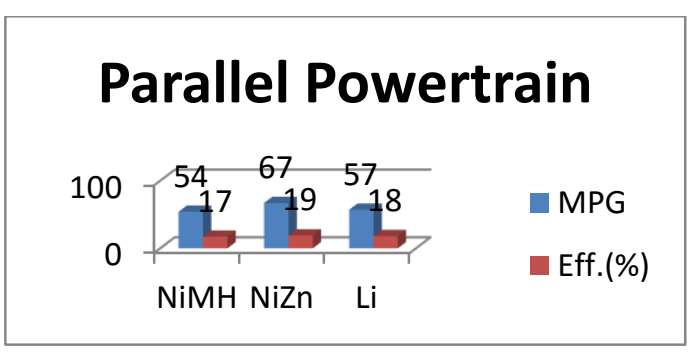

Fig.14: Battery performance for Parallel configuration

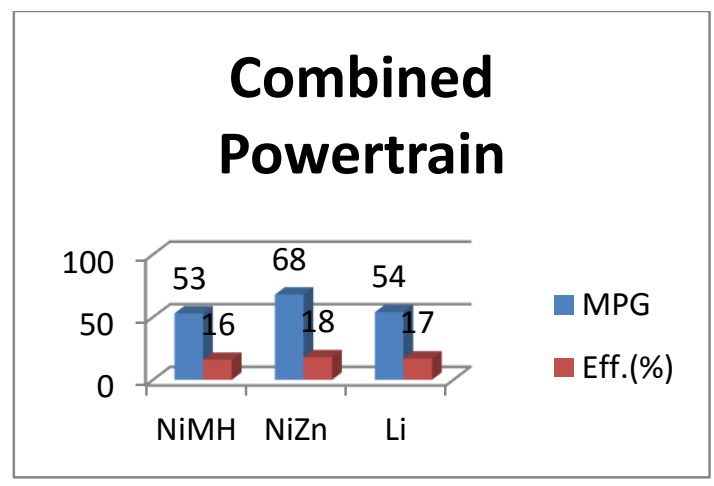

Fig.15: Battery performance for Combined configuration 


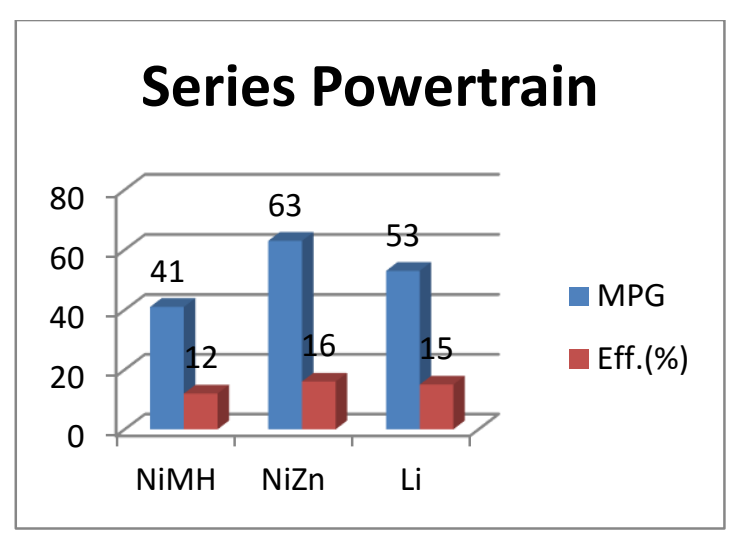

Fig.16: Battery performance for Series configuration

On the hand, average values for High way economy cycle show marginal gains in both fuel economy and system efficiency for Li battery. Indicating that where constant power is needed from the batteries and at higher speeds, Li ion batteries gives the best performance (Fig.17).

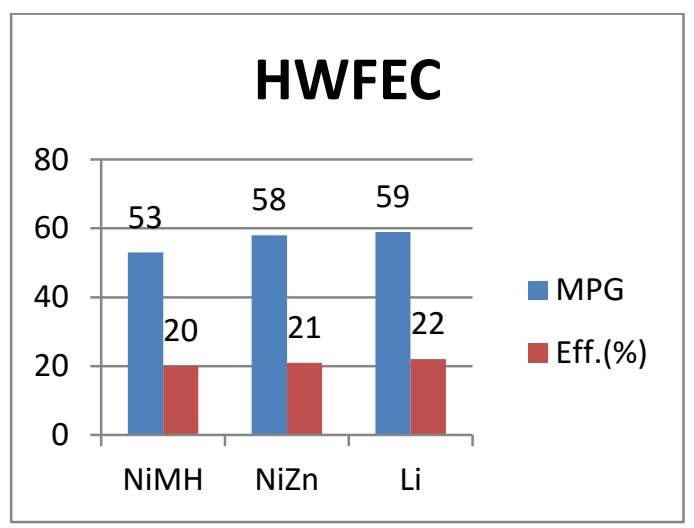

Fig.17: Battery performance for HWFEC

\section{Conclusion}

It is quite obvious from the re sults that the type of energy storage system used on an HEV has a tremendous effect on the fuel economy. It can also be deduced that the type of HEV owertrain and control strategy also affects the fuel economy significantly. Under a highway fuel economy cycle, Lithium showed the best fuel economy and system efficiency. However, average results show NiZn is most preferable for all cycles in terms of fuel economy and overall system efficiency. Also for almost all the cycles and for all Powertrains, NiMH showed the worst performance. It can be concluded that $\mathrm{NiMH}$ which is the most used energy storage systems today in the HEV industry is not the best.

Today, automotive industries are almost convinced that Lithium batteries are the way to go. This research also showed that the future of $\mathrm{HEV}$ batteries does not lie exclusively with Lithium batteries as has been portrayed in many research papers. The results show that NiZn battery is the way to go. PowerGenix Company has given proof that in terms of cost, recyclability, environmental impact, specific energy and power. Lithium batteries boast of higher specific energies, but very high cost $(50 \%$ greater cost than $\mathrm{NiMH}$ ) coupled with inability to be recycled and the danger it poses to the environment contradicts what the hybrid electric vehicle stands for. It is incumbent alternative batteries for HEV's are considered. PowerGenix NiZn, is by far superior to any of the Lithium batteries. Batteries already contribute tremendously to the cost of $\mathrm{HEV}$ cars making them difficult to sell. Considering also that hybrid vehicles are sold on the platform of environmental safety, NiZn batteries stand a better chance compared to Lithium batteries.

Due to their higher power density than batteries, further research should consider the development of electrochemical capacitor or super capacitors as energy storage systems for batteries.

\section{References}

Arbizzani, C., De Giorgio, F. \& Mastragostino, M. 2015. 4 - Battery parameters for hybrid electric vehicles. In: TILLMETZ, B. S. G. (ed.) Advances in Battery Technologies for Electric Vehicles. Woodhead Publishing.

Ayetor, G. K., Gyamfi, G. B. \& Larnor, E. T. 2013. Drive Cycle Performance of HybridElectric Vehicles. The Second Edition of the International Journal of Technology and Management Research, 1, 1-6.

Bayindir, K. Ç., Gözüküçük, M. A. \& Teke, A. 2011. A comprehensive overview of hybrid electric vehicle: Powertrain configurations, powertrain control techniques and electronic control units. Energy Conversion and Management, 52, 1305-1313.

Cao, J. \& Emadi, A. 2012. A new battery/ultracapacitor hybrid energy storage system for electric, hybrid, and plug-in hybrid electric vehicles. Power Electronics, IEEE Transactions on, 27, 122-132.

Carlson, R., Shirk, M. \& Geller, B. Factors affecting the fuel consumption of plug-in hybrid electric vehicles. The 25th international battery, hybrid and fuel cell electric vehicle symposium \& exposition. Shenzhen, China, 2010. 289-94.

Castaings, A., Lhomme, W., Trigui, R. \& Bouscayrol, A. 2016. Comparison of energy 
management strategies of a battery/supercapacitors system for electric vehicle under real-time constraints. Applied Energy, 163, 190-200.

Chan, B. C. 2007. The state of the art of electric, hybrid, and fuel cell vehicles. Proceedings of the IEEE, 95, 704-718.

Chung, C.-T. \& Hung, Y.-H. 2015. Performance and energy management of a novel full hybrid electric powertrain system. Energy, 89, 626636.

Cuma, M. U. \& Koroglu, T. 2015. A comprehensive review on estimation strategies used in hybrid and battery electric vehicles. Renewable and Sustainable Energy Reviews, 42, 517-531.

Dagci, O. H., Peng, H. \& Grizzle, J. W. 2015. PowerSplit Hybrid Electric Powertrain Design with Two Planetary Gearsets for Light-Duty Truck Applications. IFAC-PapersOnLine, 48, 8-15.

Dai, H., Guo, P., Wei, X., Sun, Z. \& Wang, J. 2015. Anfis (adaptive neuro-fuzzy inference system) based online SOC (State of Charge) correction considering cell divergence for the EV (electric vehicle) traction batteries. Energy, 80, 350-360.

Dong, J., Liu, C. \& Lin, Z. 2014. Charging infrastructure planning for promoting battery electric vehicles: An activity-based approach using multiday travel data. Transportation Research Part C: Emerging Technologies, 38, 44-55.

Egbue, O. \& Long, S. 2012. Barriers to widespread adoption of electric vehicles: An analysis of consumer attitudes and perceptions. Energy policy, 48, 717-729.

Farmann, A., Waag, W., Marongiu, A. \& Sauer, D. U. 2015. Critical review of on-board capacity estimation techniques for lithium-ion batteries in electric and hybrid electric vehicles. Journal of Power Sources, 281, 114130.

Hwang, J.-J., Hu, J.-S. \& Lin, C.-H. 2015. Design of a range extension strategy for power decentralized fuel cell/battery electric vehicles. International Journal of Hydrogen Energy, 40, 11704-11712.

Lee, D. W. \& Hogt, R. M. 2010. Hybrid electric vehicle. Google Patents.

Offer, G. J., Howey, D., Contestabile, M., Clague, R. \& Brandon, N. 2010. Comparative analysis of battery electric, hydrogen fuel cell and hybrid vehicles in a future sustainable road transport system. Energy policy, 38, 24-29.

Parks, K., Denholm, P. \& Markel, A. J. 2007. Costs and emissions associated with plug-in hybrid electric vehicle charging in the Xcel Energy Colorado service territory. National Renewable Energy Laboratory Golden, CO.

Sabri, M., Danapalasingam, K. \& Rahmat, M. 2016. A review on hybrid electric vehicles architecture and energy management strategies. Renewable and Sustainable Energy Reviews, 53, 1433-1442.

Song, Z., Hofmann, H., Li, J., Han, X. \& Ouyang, M. 2015. Optimization for a hybrid energy storage system in electric vehicles using dynamic programing approach. Applied Energy, 139, 151-162.

Sulaiman, N., Hannan, M. A., Mohamed, A., Majlan, E. H. \& Wan Daud, W. R. 2015. A review on energy management system for fuel cell hybrid electric vehicle: Issues and challenges. Renewable and Sustainable Energy Reviews, 52, 802-814.

Sun, F., Xiong, R. \& He, H. 2016. A systematic stateof-charge estimation framework for multicell battery pack in electric vehicles using bias correction technique. Applied Energy, 162, 1399-1409.

Tate, E., Harpster, M. O. \& Savagian, P. J. 2008. The electrification of the automobile: from conventional hybrid, to plug-in hybrids, to extended-range electric vehicles. $S A E$ international journal of passenger cars-electronic and electrical systems, 1, 156-166.

Walker, W. Q. 2015. 14 - Rechargeable lithium batteries for aerospace applications. In: FRANCO, A. A. (ed.) Rechargeable Lithium Batteries. Woodhead Publishing.

Yilmaz, M. \& Krein, P. T. 2013. Review of battery charger topologies, charging power levels, and infrastructure for plug-in electric and hybrid vehicles. Power Electronics, IEEE Transactions on, 28, 2151-2169. 